operation on head and neck apart from sub-total thyroidectomy, tracheostomy and subtemporal decompression; no thoracic procedure apart from the drainage of a pleural abscess; no orthopædic procedure apart from mid-thigh amputation and tendon and nerve suture; and no operation upon the pancreas. No doubt it is intended to include some of these in the second volume.

This book should be of some help to the surgical registrar and to the candidate preparing for his Fellowship, but its price, which is high in relation to its scope, will probably relegate it to the hospital library.

\section{Handbook of Physiology}

\section{Section I: Neurophysiology. Vol. 3}

Editor-in-Chief: JoHN Field. Pp. $v+2,013$ Washington, D.C.: American Physiological Society. Distributed in England by Baillière, Tindall \& Cox. 1960. 160s.

The ambitious project of the American Physiological Society in producing a multi-volume handbook is probably already well known to readers. The scope of the project is indicated by the fact that this volume, which is the third in the section of neurophysiology, runs into 2,013 pages. It comprises a series of articles, each by an expert in the field. The articles cover the borderland between what we somewhat arbitrarily call neurophysiology and equally arbitrarily psychology. Learning, motivation, perception and speech are among the subjects covered.

In the latter part of the volume the cerebral circulation, intracranial fluids and cerebral metabolism are dealt with. The book is primarily one for reference, but the individual articles make satisfactory and often enjoyable reading.

\section{Malformations of the Face}

D. Greer Walker, M.A., M.D., B.CH., M.DENT.SC., F.D.S.R.C.s. Pp. xii +202 , illustrated. Edinburgh and London: E. \& S. Livingstone. 196r. 37s. $6 d$.

Malformations of the face are not uncommon, but heretofore problems of treatment have tended to overshadow the study of probable causes. The author sets out to consider the nature of these corditions with their similarities and differences in the light of modern embryology. Apart from gross errors anomalies are vestigal or nascent . . . 'the foundation of our heritage'. They arise from complicated interaction of environment and genes, and for all we know these latter may not be specific and may be capable of producing diverse structural anomalies. In spite of the difficulties rethinking on the nature and purpose of such variations is invited.

Hyperteleorism, with its many causes, is discussed at length, and prominence is afforded Greig's variety where in association with a first arch failure the approximation of the eyes which normally brings binocular vision is arrested.

Asymmetry of the skull is also well explored in regard to causation, and neck flexion in utero is shown to be responsible for mandibular deformity and a probable explanation of the Pierre Robin syndrome.

A chapter is devoted to environmental hazards of the fetus such as necrosis of the auricle and related parts, and finally there is a full description of the Treacher Collins and Klippel Feil syndromes which by their constancy suggest influence from heredity.

The work is well produced and liberally illustrated with clear photographs and drawings. It is actuated by the commendable motive of relating pathology to embryology, studies which must become increasingly interdependent. Arguments are well set out though parts are not easy to read.

\section{Congenital Deformities}

Gavin C. Gordon, M.B., F.R.c.s.e. Pp. vvi $+128 \mathrm{c}$ illustrated. Edinburgh and London: E. \& $\mathrm{S}$ Livingstone. 1961. 37s. $6 \mathrm{~d}$.

A wide field of reading, a habit of philosophic cono templation, and careful observation and experiment areo the three pillars which characterise the best medica厉 writing through the ages. The stream of thought is a broad one with many tributaries. In a small and modest way Gavin Gordon's monograph on congenital de-n formities belongs to this classical tradition.

The main part of his work deals with the 'cause' of congenital his dislocation. He emphasizes the importance of early development, the part played by the $\vec{\omega}$ ligament of Bigelow and, a challenging notion, denieso the influence of mechanical pressure in the developmento of congenital dislocation. His studies lead on to a dis $\frac{0}{3}$ cussion of how the excessively flexed position of the hips in utero may, by vascular compression, lead tow the later development of pseudocoxalgia, slipped upper femoral epiphysis and osteoarthritis. Because his theories. are of a fundamental nature he is able to apply them in a useful and interesting way to such problems as the value of McMurray's osteotomy, the pathology of acute osteomyelitis and the mechanism of fracture healing. Even spasticity and mental processes are con음 sidered, though here it must be admitted the link appears somewhat tenuous.

The reader seeking facile explanations and glibm summaries with a view to passing examinations will find this book frustrating and of little value. He shogf $\overrightarrow{6}$ place it on a shelf just out of easy reach but not outoge sight; then, when time no longer presses, he show read it and re-read it; for it both widens the horisis and stimulates thought.

\section{Chemistry of Cancer Toxin Toxohormone}

W. Nakahara, PH.D., M.D. and F. FukuOKa, M.D요 American Lectures in Living Chemistry, Ed. I. Newton Kugelmass. Pp. xiv +75 , illustrated $\overrightarrow{\bar{D}}$ Springfield, Illinois: Charles C. Thomas. Oxford: Blackwell. 1961. 34s.

In the past attempts to isolate a toxic product of malignant tissue capable of accounting for the cachexiaaccompanying malignant disease have failed, and the cachexia is usually regarded as a consequence of non specific secondary factors. Twenty years ago Greenstein demonstrated that the liver catalase activity was. greatly reduced in animals bearing malignant tumours $?$ and Nakahara and Fukuoka followed up this observation in the hope that it could provide evidence on the possible existence of a specific cancer toxin. They succeeded in isolating a polypeptide from malignant tissue which powerfully depressed liver catalase activity in normato animals. Later, it was found that the polypeptide interferes with iron metabolism, and the depression of catalase activity was one consequence of this, for catalase is an iron-protein enzyme, and the polypeptide $N$ was found to inhibit the incorporation of iron into its prosthetic group. The authors describe the researches on this substance simply and clearly, but it is unfortunate that the name toxohormone was given to it, for somethinge very like it is apparently present in normal tissues, admittedly in much smaller amounts than in malignante tissue with which it is evidently always associated. It seems most unlikely that toxohormone plays any partin the causation of malignant cachexia; the story of the discovery and characterisation of this polypeptide is, $\Omega$ 